\title{
Analise da adesão às tendências da Ciência pelos repositórios institucionais brasileiros
}

\author{
Analysis of adhesion in the trends of Science by Brazilian institutional repositories
}

\author{
Milton Shintaku \\ Doutor em Ciência da Informação pela Universidade de Brasília - UnB. \\ Coordenador de Articulação, Geração e Aplicação de Tecnologia do IBICT \\ E-mail: milton.shintaku@gmail.com
}

\begin{abstract}
Claudio Duque
Doutor em Ciência da Informação pela Universidade Federal de Minas Gerais - UFMG. Professor Adjunto da Faculdade de Ciência da Informação da Universidade de Brasília - UnB.

E-mail: klaussherzog@gmail.com

Emir José Suaiden

Doutor em Ciência da Informação pela Universidad Complutense de Madrid, Espanha. Professor titular da Faculdade de Ciência da Informação da Universidade de Brasília - UnB.

E-mail: $\underline{\text { emir@unb.br }}$
\end{abstract}

\section{Resumo}

Repositório institucional tem se tornado o locus para depósito da produção acadêmica das universidades e institutos de pesquisa, tornando-se instrumento valioso para a disseminação da informação científica. Entretanto, como ferramentas informatizadas, requerem constante atualização, vistos ao dinamismo tecnológico. Da mesma forma, por servir a disseminação da informação científica, deve estar em consonância com as tendências da ciência. Nesse sentido, o presente estudo visa levantar e analisar a adesão dos repositórios brasileiros em relação a: Dados Abertos; Arquivos Abertos; Acesso Aberto; Ciência Aberta; Curadoria Digital e e-science. Para tanto, faz uso de uma abordagem quantitativa, utilizando um survey com os gestores dos repositórios institucionais brasileiros. Revelou-se, assim, um cenário ainda incipiente, mas promissor na adesão às tendências da Ciência, em que a maior adesão dá-se ao Acesso Aberto. Assim, o presente estudo contribui para a discussão sobre os repositórios institucionais brasileiros.

Palavras-chaves: Repositórios Institucionais. Tendências da Ciência. Dados Abertos. Arquivos Abertos. Acesso Aberto. Ciência Aberta. Curadoria Digita.; e-science.

\begin{abstract}
The institutional repository has become the locus for holding the academic production of universities and research institutes, becoming a valuable tool for the dissemination of scientific information. However, because of the technological dynamism, repositories, as computerized tools, require constant updating. Similarly, to serve the dissemination of scientific information, they should be in line with the trends of science. In this sense, this study aims to survey and analyze the adherence of Brazilian repositories regarding: Open Data; Open archives; Open Access; Open science; Digital curation and e-science. To this end, a quantitative approach was adopted, administering a survey to the managers of Brazilian institutional repositories. The research revealed a still-incipient stage, but promising in relation to adherence to the trends in science, where the largest support is given to Open Access. Thus, this study contributes to the discussion surrounding Brazilian institutional repositories
\end{abstract}

Keywords: Institutional Repositories. Science Trends. Open Data. Open Archives. Open Access. Open Science. Digital Curation. e-science.

InCID: R. Ci. Inf. e Doc., Ribeirão Preto, v. 6, n. 2, p. 148-169, set. 2015/fev. 2016.

DOI: 10.11606/issn.2178-2075.v6i2p148-169 


\section{Introdução}

A consolidação dos repositórios institucionais de cunho científico, mantidos por universidades e institutos de pesquisa, tem alterado algumas práticas da ciência, principalmente, no que diz respeito ao acesso a publicações com resultados de pesquisa. Tanto que, Bjork (2005) e Costa (2008), nos modelos de comunicação científica, colocam os repositórios como ferramentas para facilitar o acesso à produção científica e, com isso, apoiar a disseminação e o uso da informação.

Os repositórios estão em um contexto maior, relacionado com o uso de ferramentas informatizadas nos processos científicos, ou seja, em todas as etapas da pesquisa. Hurd (2000), prevendo a modernização e transformação dos procedimentos para geração da informação científica, propõe um modelo para 2020, em que a informação digital é constante, com a colaboração, a disseminação e preservação da informação sendo efetuadas por intermédio de ferramentas disponíveis na internet.

Neste cenário ainda em processo de adequação, a tecnologia se apresenta como peça fundamental. Permeiam as etapas da pesquisa, em que a documentação intermediária é produzida em formato digital, a coleta de dados é feita por intermédio de equipamentos, em que os dados são armazenados em bancos de dados e o resultado da pesquisa é publicado em formato digital. Reforça-se, dessa forma, a presença da tecnologia apoiando os processos.

É nesse contexto que o presente estudo se insere, na análise dos repositórios frente às mudanças da Ciência, visto que os repositórios já fazem parte dos processos da comunicação científica. Levantar o cenário sobre a aderência dos repositórios brasileiros frente às tendências atuais da Ciência. Com isso, colaborar com os estudos sobre repositórios institucionais, como ferramenta para disseminação e preservação da produção científica de uma instituição.

O papel atual dos repositórios e a velocidade que a tecnologia evolui conforma um aspecto que requer estudos devido à interdisciplinaridade do tema. Abriga-se na Ciência da Informação, com todos os vieses, ao passo que trata de como a Ciência está se configurando em uma futura era totalmente digital e como os repositórios brasileiros estão se preparando. 


\section{Tendências na Ciência e os Repositórios Científicos}

A Ciência tem evoluído rapidamente, na especialização com a criação de novas áreas de estudo e nas relações disciplinares de alguns temas, criando novos métodos de coleta, armazenamento e formas de análise dos dados. Da mesma forma que tem aprimorado os canais de publicação de resultados de pesquisa, com o uso cada vez maior da tecnologia. Com isso, tem facilitado o acesso à informação, tornando o processo mais democrático.

Assim, algumas disciplinas têm aderido a tendências mais atuais, principalmente àquelas mais tecnológicas, como as engenharias. Mesmo nas mais tradicionais, a internet tem imprimido reflexos perceptíveis. A comunicação informal via e-mails, por exemplo, tem se transformado numa forma trivial, mesmo nos processos de pesquisa. Para tanto, o estudo das tendências da Ciência revela-se importante no entendimento da própria Ciência atual.

\section{$\underline{\text { Acesso Aberto }}$}

O Movimento de Acesso Aberto (Open Access) centra-se na disseminação dos resultados de pesquisa sem ônus. Nascido no âmbito das disciplinas das Ciências Exatas ou Duras tem se expandido para outras áreas do conhecimento, principalmente para as Ciências Sociais, apresentando um grande impacto na Comunicação Científica. Este movimento tem alterado a comunicação científica mundialmente, como relata Gasparyan, Ayvazyan e Kitas (2013).

O Acesso Aberto nasce como um novo modelo para o negócio das publicações de revistas científicas. Para Suber (2012) o Acesso Aberto é a literatura no formato digital, disponível online, de forma gratuita, livre de barreiras para acesso, remetendo a definição que a Declaração de Budapest apresenta como:

\footnotetext{
Por "acesso aberto" a esta literatura, nos referimos à sua disponibilidade gratuita na internet, permitindo a qualquer usuário a ler, baixar, copiar, distribuir, imprimir, buscar ou usar desta literatura com qualquer propósito legal, sem nenhuma barreira financeira, legal ou técnica que não o simples acesso à internet. A única limitação quanto à reprodução e distribuição, e o único papel do copyright neste domínio sendo o controle por parte dos autores sobre a integridade de seu trabalho e o direito de ser propriamente reconhecido e citado. (SUBER, 2012, p. 4)
}

InCID: R. Ci. Inf. e Doc., Ribeirão Preto, v. 6, n. 2, p. 148-169, set. 2015/fev. 2016. 
Em editorial, Van Meervelt (2015) advoga pela adoção desse movimento, relatando que muitas universidades e instituições de fomento tem apoiado a publicação livre de barreiras, pois dão visibilidade a pesquisa, autor e instituição. Para a sua implementação, duas ferramentas se destacam, os periódicos de acesso aberto e os repositórios, denominados por Harnad et al (2004) de via dourada e via verde, respectivamente. Os resultados de pesquisas são publicados em revistas de acesso livre e os repositórios as preservam e dão acesso à produção, inclusive de documentação publicada de forma restrita e aberta pelos editores.

Passerini de Rossi (2012) afirma que o movimento de acesso aberto é especialmente importante para países em desenvolvimento, por possibilitar o acesso sem barreiras às informações científicas mais atualizadas. Da mesma forma que facilita o acesso às publicações, cria oportunidades dos autores desses países em publicar suas pesquisas, disseminando-as livremente, potencializando a sua visibilidade.

Entretanto, o modelo de publicação em acesso aberto enfrenta problemas, entre eles, a sobrecarga no processo de avaliação pelos pares, como relata Arns (2014). Esse indício revela a necessidade de repensar o modelo atual adotado por revistas de acesso aberto, principalmente o processo de submissão, como destaca o autor.

A sustentabilidade do modelo do acesso aberto ainda é muito discutida, principalmente para as revistas. A opção de atribuir os custos aos autores tem sofrido ataques, como apresenta Rizor et al. (2014), revelando a necessidade de desenvolvimento de modelos de publicação sustentável de acesso aberto, apoiado por instituições de fomento.

Os repositórios institucionais, por sua vez, nascem no âmbito do acesso aberto como uma ferramenta representativa deste movimento, sem competir com as revistas na oferta de acesso. Um locus para a preservação, que expande a oferta de acesso por conter documentos embargados ou liberados. Com o consentimento dos editores e das editoras, abre-se o acesso à literatura científica via internet.

InCID: R. Ci. Inf. e Doc., Ribeirão Preto, v. 6, n. 2, p. 148-169, set. 2015/fev. 2016. 


\section{$\underline{\text { Arquivos abertos }}$}

Os arquivos abertos, originalmente em inglês Open Archives, muitas vezes são confundidos com o Open Access (Acesso Aberto), pois tanto em Português, quanto em Inglês, possuem a mesma sigla OA (inglês) e AA (Português). Há também certa proximidade semântica, visto que, os dois termos tratam das questões sobre fontes livres de documentos científicos no âmbito da Comunicação Científica. Destaca-se que muitas ferramentas voltadas para o acesso aberto implementam os preceitos dos arquivos abertos.

Costa (2006) relaciona os arquivos aberto e o acesso aberto na denominada "Filosofia aberta", juntamente com softwares livres. Com isso, tem-se por objetivo a criação de sistemas de informação, disponíveis na web, construídos com software livre para ofertar acesso aberto à literatura científica e promover a interoperabilidade.

O arquivo aberto é complementar ao acesso aberto, pois o primeiro tem características mais filosóficas e políticas, enquanto o segundo é mais técnico e tecnológico. Os preceitos do arquivo aberto, como apresentado na Convenção de Santa Fé, Novo México, ocorrido em outubro de 1999, são apresentados sumarizados no quadro abaixo (Quadro 1):

InCID: R. Ci. Inf. e Doc., Ribeirão Preto, v. 6, n. 2, p. 148-169, set. 2015/fev. 2016. 
Milton Shintaku, Claudio Duque e Emir José Suaiden

\section{Quadro 1 - Sumário dos conceitos dos arquivos abertos}

\begin{tabular}{|c|c|c|}
\hline \multicolumn{3}{|r|}{ Sumário dos conceitos do arquivo aberto } \\
\hline Parâmetro & Tipo & Descrição \\
\hline \multirow[t]{2}{*}{$\begin{array}{l}\text { Componentes } \\
\text { fundamentais }\end{array}$} & $\begin{array}{l}\text { Mecanismo de } \\
\text { submissão }\end{array}$ & $\begin{array}{l}\text { O sistema que gerencia documentos digitais deve implementar sistemas de } \\
\text { submissão que permita o autor depositar sua produção intelectual, sem a } \\
\text { necessidade de intermediário. }\end{array}$ \\
\hline & $\begin{array}{l}\text { Mecanismo de } \\
\text { preservação }\end{array}$ & $\begin{array}{l}\text { O sistema que gerencia documentos digitais deve implementar estratégia para } \\
\text { preservar os documentos por longos períodos de tempo. }\end{array}$ \\
\hline \multirow[t]{2}{*}{$\begin{array}{l}\text { Tipos de } \\
\text { sistemas }\end{array}$} & $\begin{array}{l}\text { Provedor de } \\
\text { dados }\end{array}$ & $\begin{array}{l}\text { É o sistema que gerencia documentos digitais, ofertando as funcionalidades aos } \\
\text { autores e usuários finais do sistema além de permitir que seus metadados sejam } \\
\text { coletados pelo provedor de serviço. }\end{array}$ \\
\hline & $\begin{array}{l}\text { Provedor de } \\
\text { serviço }\end{array}$ & $\begin{array}{l}\text { Sistema que coleta metadados dos provedores de dados e oferta um mecanismo } \\
\text { de busca consolidado }\end{array}$ \\
\hline \multirow[t]{3}{*}{$\begin{array}{l}\text { Provedor de } \\
\text { dados }\end{array}$} & $\begin{array}{l}\text { Identificador } \\
\text { único }\end{array}$ & $\begin{array}{l}\text { Todo recurso disponível em arquivo aberto deve possuir um identificador } \\
\text { único, de forma a ser acessado diretamente. }\end{array}$ \\
\hline & $\begin{array}{l}\text { Conjunto de } \\
\text { metadados }\end{array}$ & $\begin{array}{l}\text { Os documentos disponíveis pelos sistemas gerenciadores de documentos } \\
\text { devem descrever os documentos por um conjunto de metadados. }\end{array}$ \\
\hline & $\begin{array}{l}\text { Camada de } \\
\text { protocolo }\end{array}$ & $\begin{array}{l}\text { Os provedores de dados devem implementar uma camada de protocolo que } \\
\text { responde à coleta de metadados proveniente do provedor de serviço. }\end{array}$ \\
\hline \multirow[t]{2}{*}{$\begin{array}{l}\text { Provedor de } \\
\text { serviço }\end{array}$} & $\begin{array}{l}\text { Manter o } \\
\text { identificador } \\
\text { único }\end{array}$ & O provedor de dados coleta os metadados e mantém o identificador único. \\
\hline & $\begin{array}{l}\text { Manter as } \\
\text { restrições }\end{array}$ & $\begin{array}{l}\text { Se o provedor de dados restringe o uso a um documento, o provedor de serviço } \\
\text { mantém a restrição, ou seja respeita as políticas adotadas pelos provedores de } \\
\text { dados. }\end{array}$ \\
\hline
\end{tabular}

Fonte: Adaptação da Santa fé convention (2001).

Com base nos preceitos dos arquivos abertos, os repositórios são provedores de dados, pois gerenciam os documentos digitais, com formas de submissão e preservação. Possibilitam a interoperabilidade, pelo uso de uma camada de protocolo Open Archives Initiative - Protocol for Metadata Harvesting (OAI-PMH), ofertando metadados aos provedores de serviço. A interoperabilidade, segundo Triska e Café (2001), é a chave dos arquivos abertos, pois possibilita que sistemas possam intercambiar informações de forma automática.

Entretanto, conforme Jailet (2005), os arquivos abertos mesmo com a sua importância, não são tão conhecidos, pois muitos acadêmicos preocupam-se com o impacto dos resultados de pesquisa e de estar acessíveis livremente, indexáveis por motores de busca, mas não se preocupam 
com a interoperabilidade por exemplo. Nesse sentido, os repositórios de acesso aberto, geralmente implementam o arquivo aberto, mas nem sempre são reconhecidos por isso.

\section{$\underline{\text { Dados Abertos }}$}

O acesso aberto tem a atuação, principalmente, na difusão sem custos dos resultados de pesquisa, ou seja, dos documentos finais, como os artigos, enfocando o processo final da pesquisa. Os dados abertos, por sua vez, atuam nos processos intermediários, tendo foco nos dados coletados na pesquisa, tendo uma abrangência maior no ciclo de geração da informação, complementando o acesso aberto.

Possibilita o compartilhamento e o reuso de dados de pesquisa, tanto que Linde (et al. 2014) relatam que o acesso aos dados de pesquisa pode possibilitar um progresso mais rápido da Ciência, ao passo que oferta aos pesquisadores uma quantidade grande de dados para reanálise, comparação, integração e validação. Gutierrez (2011), por sua vez, relaciona os Dados Abertos à produção e disseminação de dados em escala global, remetendo aos objetivos iniciais da Web. Piller (2014) destaca que os Dados Abertos se referem aos dados não confidenciais e sem características de privacidade produzidas por fundos públicos e que foram distribuídos sem restrição para uso.

Zuiderwijk e Janssen (2014), estudando as políticas governamentais holandesas sobre dados abertos, revelam que mesmo os governos incentivando o compartilhamento de dados de pesquisa, as políticas orientadoras para compartilhamento de dados requerem estudos mais completos. Verifica-se que mesmo não sendo um movimento tão novo, o Movimento de Dados Abertos ainda carece estabelecer preceitos mais abrangentes e profundos, que possam embasar políticas e procedimentos.

Piwowar e Vision (2013), estudando a relação entre citação e dados abertos, não chegaram a um resultado definitivo, mas apresenta alguns benefícios como da adoção desse movimento:

* Reutilização dos dados: citação pela utilização desses dados, trabalhos podem ser citados pela utilização dos dados de pesquisa;

* Credibilidade: trabalhos de pesquisa com dados disponíveis pode ter maior credibilidade;

InCID: R. Ci. Inf. e Doc., Ribeirão Preto, v. 6, n. 2, p. 148-169, set. 2015/fev. 2016. 
* Visibilidade: a visibilidade aumenta, na medida em que os trabalhos possuem ligações entre os dados e os documentos publicados;

Antecipação: os dados podem ser disponibilizados antes das publicações, que pode trazer benefícios à pesquisa;

Hesse, Moses e Rilley (2015), associando os preceitos dos Dados Abertos ao chamado Big Data, apresenta um cenário promissor para as Ciências Sociais. Trabalhando com o "big data to knowledge" verifica que o compartilhamento e reanálise da grande quantidade de dados existentes são profícuos para estudos, visto a quantidade e a riqueza de dados existentes sobre comportamento humano. Revelam que os dados abertos podem ser complementados com ferramentas de integração, análise e outros.

Os Dados Abertos compõem-se de um movimento amplo, com a finalidade de ofertar dados de pesquisa de forma ampla em repositórios. Repositórios se tornam ferramentas apropriadas para o acesso aberto, arquivo aberto e dados aberto, revelando a flexibilidade e adaptabilidade deste sistema, ao passo que possibilita o gerenciamento de objetos digitais. Com isso, oferta funcionalidades para as publicações, assim como os dados da pesquisa, independente do formato. Possibilita-se, dessa forma, conectar os dados com os resultados da pesquisa.

\section{Ciência Aberta}

Apresenta-se complementaridade entre os Dados Abertos, Arquivos Abertos e Acesso Aberto, em que cada qual atuações distintas e complementares. Tanto que, Lima e Lima (2013) esquematizam esses movimentos como uma evolução, no qual a Ciência Aberta é o ponto culminante, ao passo que agrega todas as ações dos movimentos anteriores, pertencendo a um mesmo contexto, conforme:

Fontes Abertas $\rightarrow$ Dados Abertos $\rightarrow$ Acesso Aberto $\rightarrow$ Ciência Aberta

A Ciência Aberta agrega novas práticas, mas mantém as retrospectivas, pertencentes aos outros movimentos. Essas novas práticas têm relação com o uso mais frequente da tecnologia em 
todas as etapas da pesquisa, com uso de ferramentas para coleta, análise, armazenamento e preservação dos dados, disponibilizando-os e publicando os resultados de forma aberta.

Numa abordagem econômica, Borgman (2007) destaca que a Ciência Aberta é baseada na premissa que a informação científica é um bem público, o qual se torna passível de compartilhamento sem que haja perda de valor e não pode ser manter exclusivo. Contextualiza a Ciência numa abordagem mais social, alinhando com que Bjork (2005) afirma ser o propósito da Ciência de ofertar melhores condições de vida. Nesse mesmo sentido, Nielsen (2011) difere indústria de universidade, no que diz respeito às pesquisas, ressaltando que a universidade financiada por verbas governamentais deve gerar bens públicos.

Crosas et al. (2015) revela que a utilização de técnicas de Big Data se torna profícuas na Ciência Aberta, mas requer cuidado e ferramentas apropriadas, principalmente pela quantidade de dados existente, que impossibilita a análise feita localmente, e pela sensibilidade de alguns dados de pesquisa. Hey e Payne (2015) alerta para a qualidade das ferramentas a serem utilizadas na Ciência Aberta, para a obtenção de melhores resultados.

Albagli, Clinio e Raychtock (2014) sumarizam as vertentes da Ciência Aberta, apresentando os principais pontos. Exclusivamente para os repositórios, pode-se destacar:

* Educacão Aberta: Uso de repositórios como ferramenta para depósito de objetos educacionais, com o intuito de compartilhar, reusar, recriar etc;

* Ciência Cidadã: Uso de repositórios no processo de submissão de pesquisas efetuadas por não acadêmicos;

Pesquisa Aberta: Repositório com o papel de intermediar as discussões sobre os conteúdos do acervo.

A Ciência Aberta é um meio de democratização da Ciência, envolvendo questões tecnológicas, culturais, jurídicas e outros, requerendo adaptação, pois o uso da tecnologia e a disseminação aberta na Ciência, praticamente, são irreversíveis. Neste ponto os repositórios se apresentam como parte desta nova abordagem, visto que se torna o locus de depósito de todas as informações científicas, independente se intermediário ou final. São ferramentas democráticas, que ofertam serviços de informação à comunidade.

InCID: R. Ci. Inf. e Doc., Ribeirão Preto, v. 6, n. 2, p. 148-169, set. 2015/fev. 2016. 


\section{$\underline{\text { Curadoria Digital }}$}

Com as novas práticas da Ciência, o uso da tecnologia e os dados em formato digital surgem a necessidade de ferramentas que apoiem essas novas práticas. É neste contexto que surge a Curadoria Digital, que como destaca Sales e Sayão (2014), um conjunto de procedimentos que envolvem a manutenção, preservação e adição de valor aos dados digitais de pesquisa, apoiando todo o ciclo de vida. Conforme a definição do Digital Curation Centre (DCC), apresenta-se as ações para cada etapa do ciclo, no quadro a seguir (Quadro 2):

\section{Quadro 2 - Etapas do ciclo documental}

\begin{tabular}{|c|c|}
\hline Etapa & Descrição \\
\hline Desenvolvimento & Etapa para conceber e criar objetos digitais, envolvendo métodos de captura e armazenamento. \\
\hline Criação & $\begin{array}{l}\text { Etapa de produção dos objetos digitais e caracterizando-os com metadados descritivos, administrativos, } \\
\text { estruturais entre outros. }\end{array}$ \\
\hline Acesso e uso & Ofertar aos usuários uma forma fácil de acesso aos objetos digitais de forma livre ou restrita. \\
\hline $\begin{array}{l}\text { Avaliação e } \\
\text { seleção }\end{array}$ & $\begin{array}{l}\text { Avaliar os objetos digitais de forma selecionar os que requerem curadoria e preservação por longos } \\
\text { períodos, alinhados com recomendações, questões legais, políticas e outros adotados pela instituição. }\end{array}$ \\
\hline Descarte & $\begin{array}{l}\text { Utilizar formas de descarte de objetos digitais com base em recomendações, questões legais, políticas e } \\
\text { outros adotados pela instituição. }\end{array}$ \\
\hline Alimentação & $\begin{array}{l}\text { Transferir objetos digitais para repositórios ou outro tipo de sistemas conforme as recomendações, } \\
\text { questões legais, políticas e outros adotados pela instituição. }\end{array}$ \\
\hline Preservação & Empreender ações que assegurem a preservação dos objetos digitais, assim como as questões de autoria; \\
\hline Reavaliação & $\begin{array}{l}\text { Por ser um ciclo, reavaliar os objetos digitais, a fim de validar as ações, visto que políticas, recomendações } \\
\text { e outros são dinâmicos e os objetos digitais podem mudar o status com o tempo. }\end{array}$ \\
\hline Armazenamento & Adotar formas seguras de manter os objetos digitais conforme padrões relevantes \\
\hline Acesse o reuso & $\begin{array}{l}\text { Assegurar que os dados estarão disponíveis para os usuários, com o objetivo de uso e reuso, podendo estar } \\
\text { aberto a todos ou restrito. }\end{array}$ \\
\hline Transformação & Criar outros formatos para o objeto digital \\
\hline
\end{tabular}

Fonte: Adaptado de Abbot, 2008

Acordando com o quadro acima, Giaretta (2011), afirma que a Curadoria se estabelece na área de pesquisa e acadêmica. Com relação às questões legais, McGinley (2007) relata que a curadoria digital é ampla, semelhante a uma lei, no qual as questões legais envolventes na curadoria são dependentes do estágio a que opera, nos vários tipos de usuários acessando os objetos digitais curados, nos variados níveis diferenciados de permissões. Autores diferem dos curadores, que por sua vez, diferem dos leitores.

InCID: R. Ci. Inf. e Doc., Ribeirão Preto, v. 6, n. 2, p. 148-169, set. 2015/fev. 2016. 
Curry Freitas e O’Riáin (2010) consideram a curadoria digital como um processo, em que um conjunto de informações confiáveis sejam geridas em repositórios, proporcionando o uso corrente ou futuro, por diversos tipos de usuários como os pesquisadores, historiadores, acadêmicos, entre outros. Siebra et al. (2013) reforçam que a preservação em repositórios devem ser implementados como estratégia mais amplas de curadoria, como forma de manter os serviços ofertados.

Expandindo o entendimento sobre processos de curadoria, Peres-Neto e Gonzales (2015) advogam que a curadoria de dados pode ser compartilhada com federações ou confederações de repositórios, assim como serviços nacionais de dados. A importância dos dados de toda a cadeia da pesquisa torna-se um bem a ser mantido pela comunidade.

\section{$\underline{\text { E-Science }}$}

O termo e-science descreve uma nova forma de fazer ciência, em que a tônica é a distribuição e a colaboração, fortemente amparada pela tecnologia. Hey e Hey (2006) afirmam que este termo foi utilizado pela primeira vez por John Taylor para descrever a utilização de grandes infraestruturas de computação para estudos colaborativos, com a participação de múltiplas disciplinas, formando redes científicas globais, que ampliam as possibilidades das pesquisas.

Neste sentido, a possibilidade de analisar grandes quantidades de dados altera a forma de se fazer pesquisa, uma revolução na Ciência, como destacam Sayão e Sales (2014). Corroborando a essa ponderação, Medeiros e Caregnato (2012) compararam o E-Science com a pesquisa tradicional apresentados no Quadro 3, destacando as diferenças: 


\section{Quadro 3 - Comparação ente o e-science e a pesquisa tradicional}

\begin{tabular}{|l|l|l|}
\hline Característica & E-Science & Pesquisa tradicional \\
\hline Participantes & $\begin{array}{l}\text { Diversamente qualificados, equipe de } \\
\text { pesquisa distribuída. }\end{array}$ & $\begin{array}{l}\text { Pesquisador individual ou pequena } \\
\text { equipe local de pesquisa }\end{array}$ \\
\hline Dados & $\begin{array}{l}\text { Gerados, armazenados e acessíveis de } \\
\text { localizações distribuídas. }\end{array}$ & $\begin{array}{l}\text { Gerados, armazenados e acessíveis } \\
\text { apenas localmente. }\end{array}$ \\
\hline $\begin{array}{l}\text { Computação e } \\
\text { instrumentação }\end{array}$ & $\begin{array}{l}\text { Larga escala, sob demanda ou acesso à } \\
\text { informação compartilhada. }\end{array}$ & $\begin{array}{l}\text { Emprego da computação em lote, ou } \\
\text { emprego do computador, ou } \\
\text { instrumentos do próprio pesquisador. }\end{array}$ \\
\hline Rede & Confiança na internet e em mediadores. & Não confiante na internet \\
\hline $\begin{array}{l}\text { Disseminação da } \\
\text { pesquisa }\end{array}$ & Via websites e portais especializados & $\begin{array}{l}\text { Via publicações impressas ou } \\
\text { apresentações em conferências }\end{array}$ \\
\hline
\end{tabular}

Fonte: Medeiros e Caregnato (2012).

Apresenta-se uma confluência nas tendências. Gray (2009) destaca o envolvimento de três ações fundamentais no e-science: a coleta, a curadoria e a análise de grande quantidade de dados. Com isso, os repositórios revelam ser uma ferramenta útil, por ter a possibilidade de gerir dados, no qual os dados coletados podem ser depositados; a Curadoria pode atuar e funcionalidades adicionais podem analisar os dados hospedados no repositório, uma ferramenta de apoio ao escience.

Transcendendo as questões mais estruturais do e-science, Narock e Fox (2011), apontam certas questões semânticas, particularmente importantes. O uso maciço da tecnologia, integração e colaboração requer ferramentas mais atualizadas para descoberta de informação, apontando as pesquisas semânticas no âmbito do e-science, com tendência viável e profícua.

O estudo do e-science no âmbito da Ciência da Informação, no entanto, ainda se apresenta incipiente, como relatam Costa e Cunha (2014), afetando muitas das suas discussões como nos repositórios, por exemplo. Destaca a urgência de estudos que apoiem esse movimento nas disciplinas vinculadas às Ciências Sociais e Humanas, com reflexo nas ferramentas voltadas à comunicação científica. 


\section{Metodologia}

Orientado pelo objetivo de levantar um cenário sobre a adesão às tendências da Ciência pelos repositórios institucionais brasileiros e analisá-lo, o presente estudo optou por uma abordagem quantitativa na coleta e qualitativa na análise dos dados. Com isso, como descreve Richardson (2008), tem-se a precisão e profundidade necessária para o estudo. Assim, alinha-se ao que Denzin e Lincoln (2006) enfatizam que as questões sociais são melhores analisadas por um viés qualitativo, mesmo que os dados sejam de cunho quantitativo.

Para a coleta de dados, optou-se por aplicar um questionário, estruturado, formado por questões de múltiplas escolhas, desenvolvido no Google-docs, respondido online. Enviou-se convite para 56 gerentes de repositórios brasileiros, vinculados às universidades e institutos de pesquisa. Tendo obtido 34 respostas, ou seja, $60 \%$ do universo delimitado. Este questionário foi categorizado para abranger três características, a adesão às tendências, a implantação de políticas voltadas às tendências e sobre as informações estratégicas.

Para a análise, propriamente dita, utilizam-se conceitos baseados na avaliação de maturidade, por tratar-se de um modelo compatível com os objetivos do estudo, possibilitando apresentar graficamente o estágio evolutivo de um sistema. Com isso, possibilita analisar o estágio atual de um sistema e, se fosse o caso, que ponto deseja-se chegar. Está técnica é mais utilizada em gestão de projetos, mas apresenta-se útil em análises de cenários.

InCID: R. Ci. Inf. e Doc., Ribeirão Preto, v. 6, n. 2, p. 148-169, set. 2015/fev. 2016. 


\section{Resultados}

No que tange à adesão às tendências da Ciência, revela-se um cenário ainda em estágio inicial. A maioria das tendências da ciência se apresenta pouco utilizadas ou desconhecidas, representando um terreno fértil a estudos com o propósito de gerar metodologias e ferramentas para implementação.

O gráfico de radar da figura 1 apresenta algumas particularidades:

* A adoção das tendências é desigual, sendo mais utilizado o Acesso Aberto e Arquivos Abertos, na linha "conheço e aplicamos no repositório";

* A relação entre "conhecer uma tendência” X “aplicar", que requer estudos mais profundos para determinar as causas, na linha “conheço, mas não aplicamos no repositório". Oportunidades de estudos pelos resultados apresentados;

* Cenário promissor com a linha "Não conheço, mas tenho interesse em conhecer";

Rejeição à tendência com a linha "não conheço" ainda baixo, reforçando o cenário promissor.

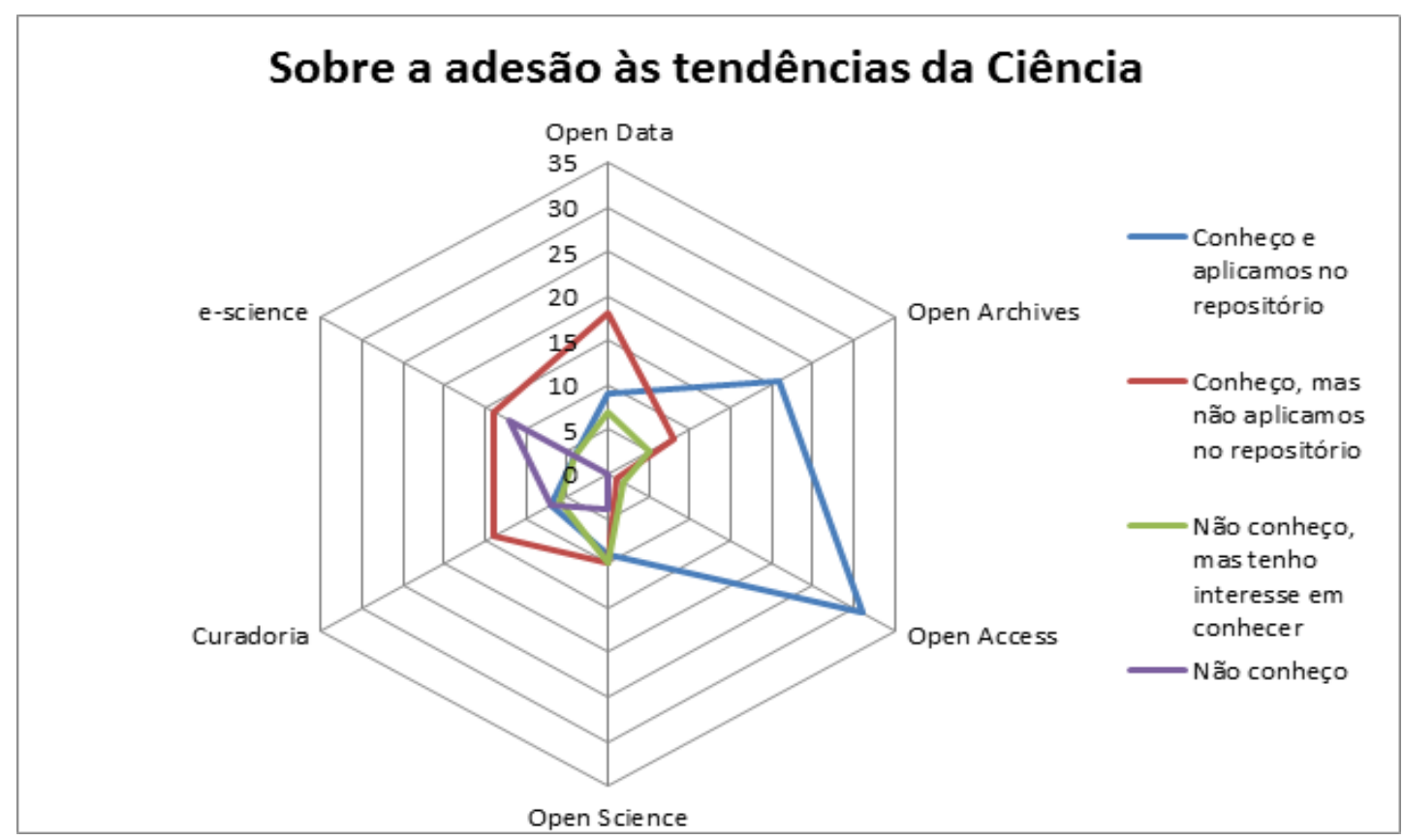

Figura 1 - Sobre a adesão às tendências da Ciência Fonte: dos autores.

InCID: R. Ci. Inf. e Doc., Ribeirão Preto, v. 6, n. 2, p. 148-169, set. 2015/fev. 2016. 
O Acesso Aberto (Open Access) é amplamente aceito e utilizado pelos repositórios estudados, seguindo a tendência mundial em disseminar a produção científica publicada, proposta pela via verde de Hanard et al. (2004). Apresenta a maior adoção entre todas as tendências estudadas, porque os repositórios são ferramentas típicas desse movimento, por isso apresenta a maior maturidade no gráfico, com ponto mais próximo à borda.

Os arquivos abertos também apresentaram uma boa adesão, mesmo que menor frequência que a o Acesso Aberto. Nota-se que grande parte das ferramentas para criação de repositórios possui funcionalidades consonantes com os arquivos abertos, com a possibilidade de autoarquivamento ou interoperabilidade, mas que nem sempre são implementados ou implementados parcialmente por questões técnicas ou tecnológicas.

O estudo ratificou os achados de Assis (2013) em que pouco repositórios implementam o autoarquivamento, mas que todos implementam a interoperabilidade, como forma de participação de federações como a Biblioteca Digital Brasileira de Teses e Dissertações ou o oasisbr, por exemplo. Todos os repositórios pesquisados respondiam à coleta automática de metadados (harvesting) via protocolo Open Archieves Initiative - Protocol Metadata Harventing (OAI-PMH).

O Open Data apresenta um cenário bem promissor, em que $52 \%$ dos gestores conhecem a tendência e $26 \%$ dos repositórios a utiliza. Os gestores podem incluir clausulas nas políticas dos repositórios relacionado à tendência, mas dependem dos autores disponibilizarem os dados da pesquisa para depósito, que possui questões éticas mais sensíveis, principalmente para as ciências humanas, relacionados à privacidade. Esse ponto pode representar certa resistência à adoção dos dados abertos. Entretanto, por não apresentar rejeições, pode significar futuras implementações, com aumento na utilização.

O Open Science mostra-se menos conhecido que as tendências anteriores e apresenta uma pequena rejeição, na medida em que poucos gestores não apresentaram interesse em conhecer (4 gestores). Essa questão deve-se, possivelmente, por essa tendência ser mais ampla, mais voltada às novas práticas da Ciência e que muitos gestores não veem reflexo no repositório. Assim, revela-se uma oportunidade de estudo tanto para questões técnicas, quanto tecnológicas, ou seja, de como implementar funcionalidades voltadas a essa tendências e desenvolvimento de novas funcionalidades.

InCID: R. Ci. Inf. e Doc., Ribeirão Preto, v. 6, n. 2, p. 148-169, set. 2015/fev. 2016. 
A curadoria, por sua vez apresenta um cenário um pouco diferente, pois é mais conhecida que utilizada, possuindo indicações de certa rejeição. Destaca-se de $41 \%$ dos gestores conhecem o tema, mas não a aplicam no repositório e $37 \%$ desconhecem, sendo que apenas $17 \%$ não conhecem e desejam conhecer. Essa tendência envolve práticas distintas e em muitos casos mais técnicas. Muitas ferramentas de repositórios ainda não possuem funcionalidades para a implementação total dessa tendência, requerendo atuação mais pontual.

O e-science apresenta um cenário menos propício de todos, não apenas pela baixa utilização (11\%), mas pela rejeição (35\%), gestores que não tem interesse em conhecer o tema, podendo representar o distanciamento do repositório dos processos científicos. Neste caso, revela, muito provavelmente, a restrição na atuação do repositório. O e-science envolve procedimentos de todas as outras tendências e está mais voltada aos processos de criação de novos conhecimentos e não apenas a disseminação da informação.

Independente da tendência, o cenário inicial se apresenta propício a outros estudos mais focados a determinado tema, ao passo que os repositórios já são instrumentos pertencentes a comunicação científica, apoiando a criação de novos conhecimentos e disseminando o existente. Nesse sentido, o cenário apresenta incipiente, muito pelos repositórios serem recentes (os mais antigos estudados tinham pouco mais de 6 anos) e que muitas tendências ainda são pouco conhecidas. Assim, revela as oportunidades de estudos mais aprofundados sobre cada uma das tendências de forma separadas, aprofundando nas questões mais críticas.

Outro ponto que retrata diretamente a adesão às tendências pelos repositórios repousa nas políticas, ao passo que formalizam a utilização de algumas tendências. Com isso, possibilita à verificação da maturidade relacionada à institucionalização de determinada tendência (Figura 2). Para tanto, o presente estudo levantou quatro políticas voltadas a três tendências, sendo:

- Política institucional para depósito dos resultados de pesquisa, relacionada ao Acesso Aberto. Institucionaliza a adesão à disseminação dos resultados de pesquisas efetuados no âmbito da instituição sem barreiras;

- Política institucional para depósito dos dados de pesquisa, relacionada aos Dados Abertos. Não significa que os repositórios terão dados, mas cria um ambiente favorável à adoção do movimento de dados aberto. Amplia a tipologia e formatos dos arquivos a formarem o acervo do repositório;

InCID: R. Ci. Inf. e Doc., Ribeirão Preto, v. 6, n. 2, p. 148-169, set. 2015/fev. 2016. 
- Política para preservação física dos arquivos e Política para seleção, depósito e descarte de documentos relacionados à Curadoria. Revela a adoção de estratégias de curadoria digital para o repositório.

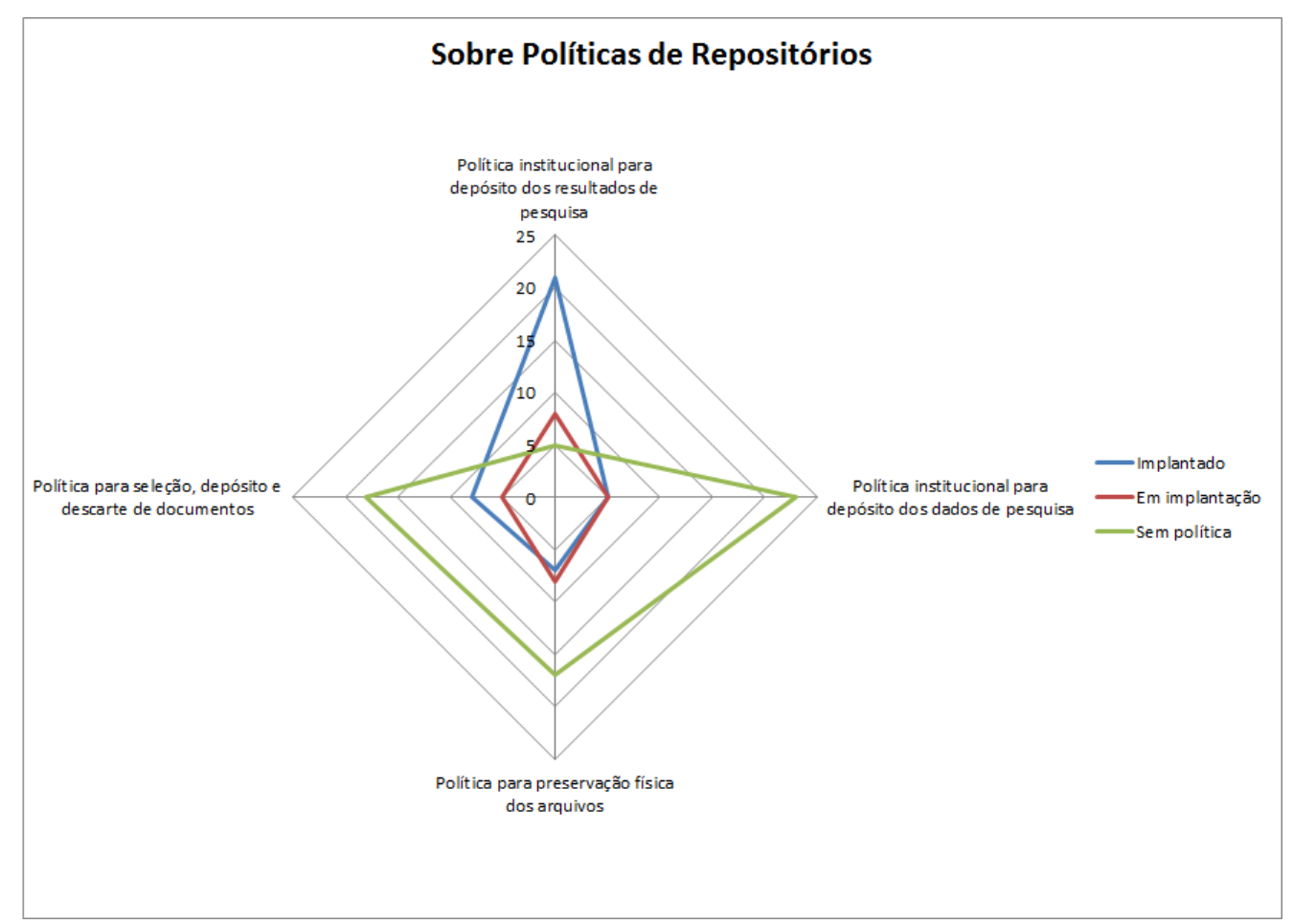

Figura 2 - Sobre Políticas de Repositórios

Fonte: os autores

Revelou-se um cenário propício aos estudos que se proponham a apoiar a definições de políticas, na medida em que grande parte dos repositórios ainda não as definiu, exceto para as políticas voltadas ao acesso aberto. Da mesma forma, apresenta a necessidade de divulgação das tendências e como pode ser desenvolvida nos repositórios, pois muitas políticas requerem apenas mudanças nos procedimentos, enquanto outras necessitam de novas funcionalidades. Nesse ponto, revelam oportunidades também para o desenvolvimento de novas funcionalidades para as ferramentas que implementam repositórios.

Destaca-se que apenas os procedimentos de depósito dos resultados de pesquisa são formalizados, ratificando que o Acesso Aberto é mais conhecido e aplicado nos repositórios de forma institucionalizada por políticas formais. Revela-se certa incipiência nas definições formais do repositório, principalmente no que se refere às outras tendências. 


\section{Considerações finais}

O cenário dos repositórios institucionais brasileiros se apresenta de certa forma homogênea no que se refere à adoção das tendências da ciência. Destaca o alinhamento dessas fontes de informação ao movimento de Acesso Aberto, contribuindo para a democratização da informação científica, potencializando a visibilidade das instituições, autores etc.

Outro ponto a ser salientado, centra-se na questão do papel do repositório. Grande parte dos repositórios é gerida pelas bibliotecas e muitos dos gestores se restringem a ofertar acesso digital a informação, explicando a grande adesão ao movimento do Acesso Aberto. Essa questão se alinha a visão tradicional da biblioteca em salvaguardar e ofertar acesso à informação. Entretanto, os repositórios apresentam com um potencial maior no processo de apoio a geração, preservação e disseminação da informação científica.

Pode-se, assim, prever um aumento da adesão a outras tendências, pois já ocorre em alguns repositórios, ainda que em número bem menor. Outro ponto que corrobora é o conhecimento ou intenção em conhecer as tendências focadas no estudo por parte dos gestores. Esse indício pode ser um facilitador à adesão, apresentando um cenário propício às outras tendências. Destaca-se que os repositórios se apresentam recentes em muitas instituições, com grande maioria completando apenas 5 anos.

Todos os repositórios avaliados são desenvolvidos com a ferramenta livre DSpace, que já se apresenta alinhado com algumas tendências, mas que dependem dos gestores para a utilização. No entanto, apresenta a necessidade de atualização tecnológica desta ferramenta para abarcar outras tendências, principalmente da Ciência Aberta e e-science, visto que possui funcionalidades ligadas ao Arquivos Abertos, Acesso Aberto, Dados Abertos e Curadoria.

Por fim, o presente estudo revelou um cenário desafiador para outros estudos ou ações, ao passo que, relaciona as tendências atuais da Ciência com os repositórios, que por si também é uma tendência. Contribuir para a discussão sobre os repositórios, seu contexto atual e as tendências.

InCID: R. Ci. Inf. e Doc., Ribeirão Preto, v. 6, n. 2, p. 148-169, set. 2015/fev. 2016. 


\section{Referências}

ABBOTT, D. What is digital curation? In: DCC briefing papers: introduction to curation. Edinburgh: Digital Curation Centre, 2008. Disponível em: <http://www.dcc.ac.uk/resources/briefingpapers/introduction-curation/what-digital-curation>. Acesso em: 29 ago. 2015.

ALBAGLI, S.; CLINEO, A.; RAYCHTOCK, S. Ciência aberta: correntes interpretativas e tipos de ação. Liinc em Revista, Rio de Janeiro, v. 10, p. 434-450, 2014. Disponível em: 〈http://revista.ibict.br/liinc/index.php/liinc/article/view/749>. Acesso em: 12 dez. 2014.

ARNS, M. Open access is tiring out peer reviewers. Nature, v. 515, n. 467, p. 467, 2014. Disponível em:

<http://www.nature.com/polopoly_fs/1.16403!/menu/main/topColumns/topLeftColumn/pdf/5154 67a.pdf>. Acesso em: mar. 2015.

ASSIS, T. B. Análise das políticas de autoarquivamento nos repositórios institucionais brasileiros e portugueses. InCID: Revista de Ciência da Informação e Documentação, Ribeirão Preto, v. 4, n. 2, p. 212-227, dez. 2013. DOI: http://dx.doi.org/10.11606/issn.2178-2075.v4i2p212-227. Disponível em: <http://www.revistas.usp.br/incid/article/view/69329>. Acesso em: 07 set. 2015.

BJÖRK, B. C. Scientific communication life-cycle model, 2005. Disponível em: 〈http://oacs.shh.fi/publications/Model35explanation2.pdf >. Acesso em: dez. 2007.

BORGMAN, C. L. Scholarship in the digital age: information, infrastructure, and the internet. Cambridge: MIT Press, 2007.

COSTA, M. M.; CUNHA, M, B. O bibliotecário no tratamento de dados oriundos da e-science: considerações iniciais. Perspectivas em Ciência da Informação, Belo Horizonte, v. 19, n. 3, p.189-206, jul./set. 2014.

COSTA, S. M. S. Filosofia aberta, modelos de negócios e agências de fomento: elementos essenciais a uma discussão sobre o acesso aberto à informação científica. Ciência da Informação, Brasília, v. 35, n. 2, p. 39-50, maio/ago. 2006.

Abordagens, estratégias e ferramentas para o acesso aberto via periódicos e repositórios institucionais em instituições acadêmicas brasileiras. Liinc em Revista, Rio de Janeiro, v. 4, n. 2, 2008. Disponível em: < http://revista.ibict.br/liinc/index.php/liinc/article/view/281>. Acesso em: abr. 2015.

CROSAS, M. et al. Automating open science for big data. Annals of the American Academy of Political and Social Science, v. 659, n. 1, 2015. 
CURRY, E.; FREITAS, A.; O'RIÁIN, S. The role of community-driven data curation for enterprises. In: WOOD, D. (Ed.). Linking enterprise data. Boston: Springer Science \& Business Media, 2010.

DENZIN, N. K.; LINCOLN, Y. S. Planejamento da pesquisa qualitativa: teorias e abordagens. Porto Alegre: Artmed, 2006. p. 367-388.

GASPARYAN, A. Y.; AYVAZYAN, L.; KITAS. G. D. Open access: changing global science publishing. Croatian Medical Journal, v. 54, n. 4, p. 403-406, 2013.

GIARETTA, D. Advanced digital preservation. New York: Springer, 2011.

GRAY, J. e-Science: a transformed scientific method. Transcrição de palestra ministrada por Jim Gray no Conselho Nacional de Pesquisa (EUA), 11 jan. 2007. In: HEY, T.; TANSLEY, S.; TOLLE, K (Ed.). The fourth paradigm: data-intensive scientific discovery. Redmond: Microsoft Research, 2009.

GUTIERREZ, C. Modeling the web of data: introductory overview. In: REASONING web: semantic technologies for the web of data. Berlin: Springer, 2011. p. 416-444. Disponível em: 〈http://users.dcc.uchile.cl/ cgutierr/papers/webModels.pdf>. Acesso em: 30 nov. 2014.

HARNAD, S. et al. The access/impact problem and the green and gold roads to open access, 2004. Disponível em: 〈http://eprints.soton.ac.uk/265852/2/serev-revised.pdf〉. Acesso em: mar. 2015.

HEY, T.; HEY, J. E-science and its implications for the library community. Library Hi Tech, v. 24, n. 4, p. 515-528, 2006.

; PAYNE, M.C. Open science decoded. Nature Physics, n. 11, 2015. Disponível em: <http://dx.doi.org/10.1038/nphys3313> Acesso em: 02 set. 2015.

HESSE, B. W.; MOSER, R. P.; RILEY, W. T. From big data to knowledge in the social sciences. The Annals of the American Academy of Political and Social Science, v. 659, n. 1 p. 16-32, 3 sept. 2015.

HURD, J. The transformation of scientific communication: a model for 2020. Journal of the American Society for Information Science, New York, v. 51, n. 14, p. 1279-1283, 2000.

JAILET, A. How the introduction of new technology into higher education is revealing a need for change. In: KINDT, M; DITTLER, U.; KAHLER, H. (Ed.). E-Learning in Europe: learning Europe. Munique: Waxmann Verlag, 2005.

LINDE, P. et al. How can libraries and other academic institutes engage in making data open. In: P.; DOBREVA, P. (Ed.). Let's put data to use: digital scholarship for the next generation. In: INTERNATIONAL CONFERENCE ON ELECTRONIC PUBLISHING, 18., 2014, Thessaloniki, Greece. Proceedings... Thessaloniki, Greece, jun. 2014. 
LIMA, J. A. L.; LIMA, V. A. O. Do open source ao open education: novos conceitos para educomunicação. In: CONFERÊNCIA BRASILEIRA DE ESTUDOS EM COMUNICAÇÃO E MERCADO - ECOM, 3., 2013, Campina Grande. Anais... Campina Grande, 2013.

MEDEIROS, J. S.; CAREGNATO, S. E. Compartilhamento de dados e e-Science: explorando um novo conceito para a comunicação científica. Liinc em Revista, Rio de Janeiro, v. 8, n .2, p. 311-322, set. 2012. Disponível em: <http://www.ibict.br/liinc >. Acesso em: 03 set. 2015.

MCGINLEY, M. The legal environment of digital curation: a question of balance for the digital librarian. Berlin: Springer, 2007.

NAROCK, T.; FOX, P. From science to e-Science to semantic e-Science: a heliophysics case study. Computers \& Geosciences, v. 46, p. 248-254, Aug. 2012.

NIELSEN, M. Reinventing discovery: the new era of networked science. Princeton: University Press, 2011.

PASSERINI DE ROSSI, B. Acceso abierto: ¿un modelo realmente abierto para investigadores de países en desarrollo? Revista argentina microbiologia, Ciudad Autónoma de Buenos Aires, v. 44, n. 4, dic. 2012. Disponível em:

<http://www.scielo.org.ar/scielo.php?script=sci_arttext\&pid=S0325-

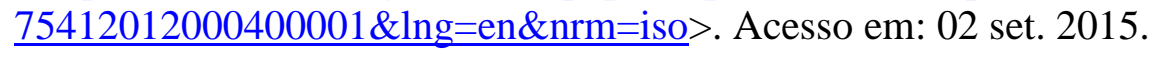

PERES-NETO, P. R.; GONZALEZ, A. Data curation act to staunch loss of research data. Nature, v. 520, n. 7548, Apr. 2015.

PILLER, R. Open data. In: HARVEY, K. (Ed.). Encyclopedia of social media and politics. Thousand Oaks: SAGE, 2014. p. 919-920.

PIWOWAR, H. A.; VISION, T. J. Data reuse and the open data citation advantage. PeerJ, v. 75, n. 1, 2013. Disponível em: < https://dx.doi.org/10.7717/peerj.175>. Acesso em: 02 set. 2015.

RICHARDSON, R. J. Pesquisa social: métodos e técnicas. São Paulo: Atlas, 2008.

RIZOR, S. L. et al. Open access goals revisited: how green and gold open access are meeting. their original goals. Journal of Scholarly Publishing, v. 5, n. 4, 2014. Disponível em: <http://dx.doi.org/10.3138/jsp.45.4.0 >. Acesso em: 02 set. 2015.

THE SANTA FÉ CONVENTION FOR THE OPEN ARCHIVES INITIATIVE: the Santa Fe Convention: the core document. 2001. Disponível em:

<http://www.openarchives.org/sfc/sfc.htm>. Acesso em: 02 set. 2015.

SAYÃO, SALES, Dados abertos de pesquisa: ampliando o conceito de acesso livre. RECIIS Revista Eletrônica de Comunicação Informação \& Inovação em Saúde, v. 8, n. 2, p.76-92, jun. 2014. Disponível em: <http://www.reciis.icict.fiocruz.br/index.php/reciis/article/view/611/1252>. Acesso em: 02 set. 2015. 
SIEBRA, S. A. et al. Curadoria digital: além da questão da preservação digital. In: ENCONTRO NACIONAL DE PESQUISA EM CIÊNCIA DA INFORMAÇÃO, 14., 2013. Anais... Rio de Janeiro, 2013.

SUBER, P. Open Access. MIT Press, 2012.

TRISKA, R., CAFÉ, L. Arquivos abertos: subprojeto da Biblioteca Digital Brasileira. Ciência da Informação, Brasilia, v. 30, n. 3, p. 92-96, set./dez. 2001.

VAN MEERVELT, L. Open access is good for you! Acta Crystallographica Section E: Structure Reports Online, v. 70, n. 8, 2015.

ZUIDERWIJK, A.; JANSSEN, M. Open data policies, their implementation and impact: a framework for comparison. Government Information Quarterly, v. 31, n. 1, p. 17-29, 2014. 